\title{
Influence of local bush wear on properties of water lubricated marine stern tube bearings
}

\author{
Wojciech Litwin, Ph. D. \\ Gdansk University of Technology
}

\section{ABSTRACT}

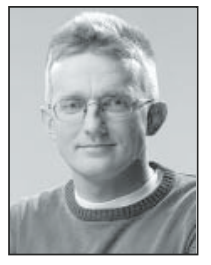

In recent years more and more frequently can be met ships in which propeller shaft water-lubricated polymer bearings have been applied. It results from their simplicity and associated relatively low initial and operational cost as compared with the complex classical sealed system based on oil-lubricated bearings. It is worth mentioning that the water-lubricated bearings are also environmentally friendly as no risk of pollution with lubricating oil used in classical systems, is involved. Design procedure of bearings in question based on materials available from their producers is relatively simple. However the calculating of such bearings creates many problems. For calculating the hydrodynamic lubricating theory is as a rule used and elastic bush flexibility taken into account. In the case of greater loads when lubricating film is very thin to achieve a proper solution is very difficult.

For this reason is proposed a novel method in which bush local wear effect can be accounted for. Such phenomenon has been observed during experimental tests of heavy-loaded water-lubricated slide bearings. With the use of the applied calculation algorithm bush local wear close to its edges can be taken into account, and - in consequence - a greater bearing capacity can be achieved.

Keywords: bearing systems; water-lubricated bearing; propeller shaft bearing systems

\section{INTRODUCTION}

In recent years water-lubricated bearings fitted with polymer bushes have been more and more commonly applied to shipbuilding, hydro power industry and water pumps. Such solution has many merits among which lack of risk of contamination of the environment by lubricants is crucial one.

Recently more and more sliding polymers capable of operating in water have been appeared on the market. Their price has been dropping that makes such solution more and more attractive. Moreover, many data on successive applications of water - lubricated bearings have appeared. Their producers have used the issues for advertising their products whose life time is estimated to about thirty years. However as results from practice such bearings behave in very different ways during operation and in the past many dangerous breakdowns resulting in ship docking or premature repairing of water turbine, happened.

The bearing lubricated with water, a low viscosity liquid, shows many limitations. Doubtlessly, it develops always a smaller hydrodynamic capacity as compared with oillubricated bearing of the same size. In addition, it shows form instability of polymer bush which, due to shrinkage mounting and water soaking, is capable of suffering large deformations. There are known many cases of propulsion shaft or rudderstock blocking due to polymer bush swelling. In order to prevent shaft seizing bush producers often recommend to increase bearing clearance, that results in lowering their hydrodynamic features. A less dangerous consequence of bush expansion during shrinkage mounting and subsequent water absorption in initial phase of its operation is rather large form deformation of its sliding surface. The effect is especially distinct if leadover longitudinal grooves necessary for heat transferring by water from friction zone, are made in the bush. In such case significant deformations occur in the vicinity of the grooves as bush material is there of the smallest thickness [1].

In calculating a water-lubricated bearing an isothermal model can be used, that highly facilitates to obtain calculation results [2]. In order to achieve reliable results for bearing hydrodynamic capacity elastic polymer bush flexibility should be accounted for. However it makes a trouble. It turns out that to precisely determine shape elasticity value is rather difficult. Usually only its approximate value is given. Hence especially in the case of more flexible materials calculation results may contain a great error, that was confirmed experimentally [3].

\section{RESEARCH PROBLEM}

The research problem in question results from the need of answering the question as to which extent water-lubricated polymer hydrodynamic bearing can be loaded.

In the Faculty of Ocean Engineering and Ship Technology, Gdansk University of Technology, have been conducted for several years experimental and theoretical projects aimed at solving a set of problems associated with water-lubricated bearings. One of the crucial research problems was to determine ultimate hydrodynamic load-carrying capacity of bearings of the kind $[4,5]$. Results of the performed experimental tests have been very promising. Polymer bearings of many kinds were tested. The shaft of the test stand was of $100 \mathrm{~mm}$ diameter, and the tested bushes were from 100 to $400 \mathrm{~mm}$ in length. The 
shaft rotational speed was varied in the range of $0 \div 11 \mathrm{rev} / \mathrm{s}$, that made it possible to obtain linear slide velocities below 3.5 $\mathrm{m} / \mathrm{s}$. From the performed tests it results that the bearings have operated in the fluid friction range even under the pressure of the order of $0.5 \mathrm{MPa}$ (Fig. 1 and 2).

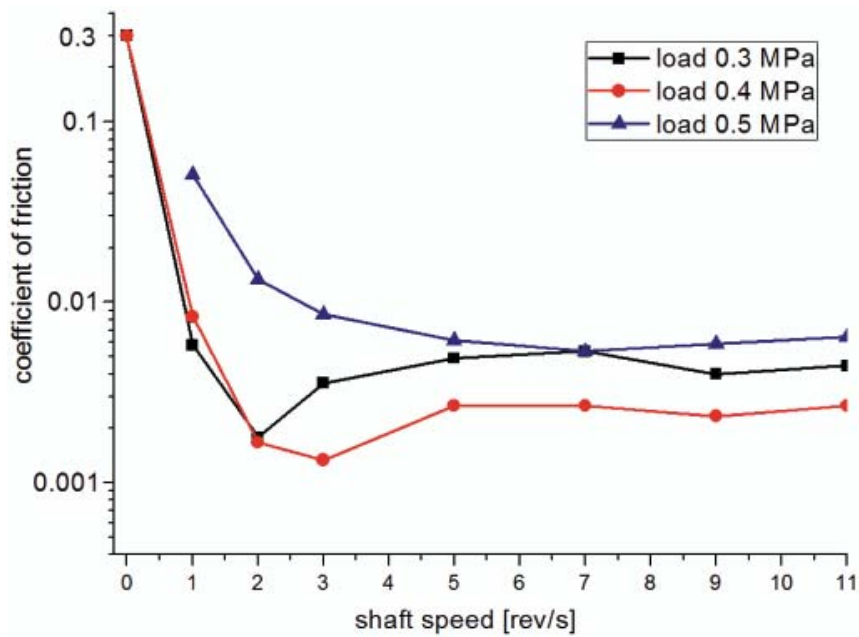

Fig. 1. Diagram of the measured friction torque converted to value of coefficient of friction, under the load up to $0.5 \mathrm{MPa}$ and at shaft rotational speed in the range of $1 \div 11 \mathrm{rev} / \mathrm{s}$

a)

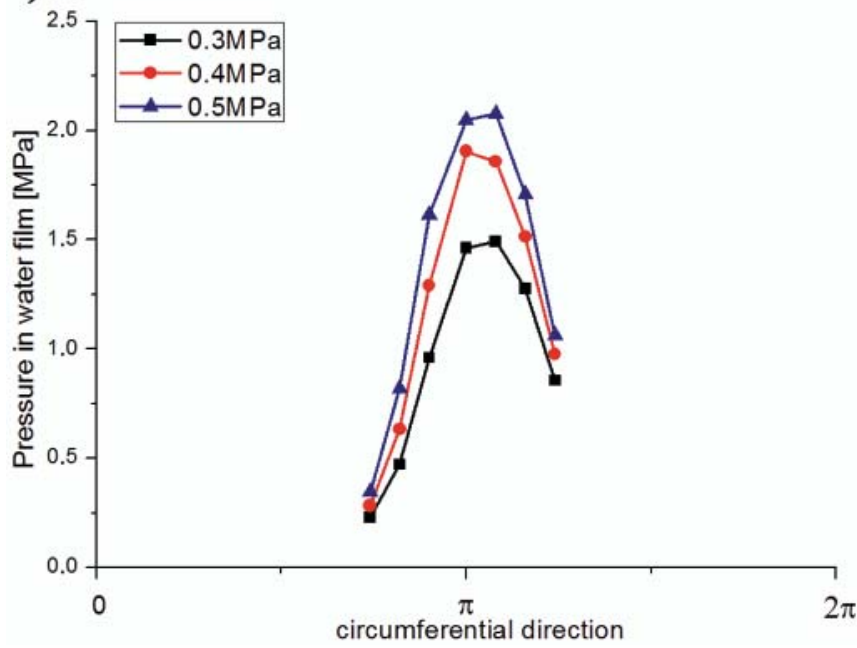

b)

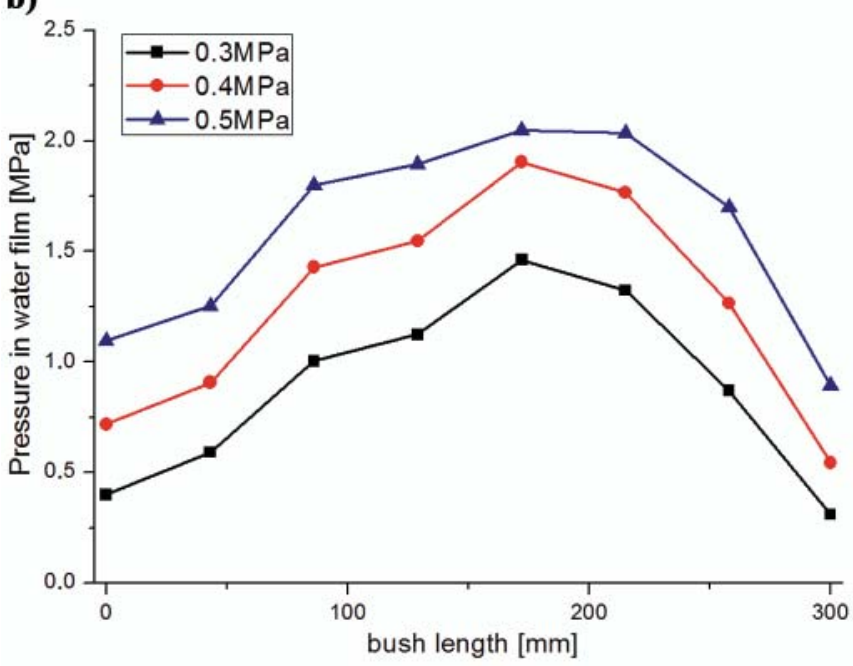

Fig. 2. The pressure distribution in bearing lubricating film, measured on the test stand at the shaft rotational speed of $11 \mathrm{rev} / \mathrm{s}$ and under the load range from 0.3 to $0.5 \mathrm{MPa}:$ a) in circumferential direction within the range of $0 \div 2 \pi, \boldsymbol{b}$ ) in longitudinal direction within the range of $0 \div 300 \mathrm{~mm}$
A serious problem is met in conducting calculations for the similar bearing by applying the hydrodynamic lubrication theory, (EHL), to bush elastic material. Namely, below certain minimum film thickness which, in the case in question, amounts to about 5 to $7 \mu \mathrm{m}$ for elastic materials, it was not possible to obtain a convergent solution. The iteration between a module which calculates pressure distribution in lubricating gap and a module which calculates elastic deformation field of bush surface has not led to any convergent solution (Fig. 3)

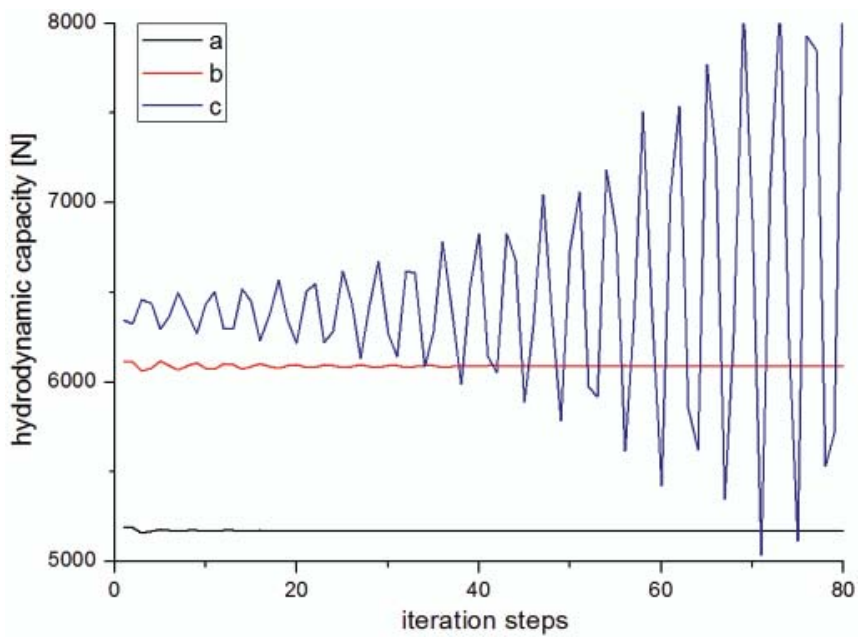

Fig. 3. An attempt to calculating hydrodynamic capacity of a heavy-loaded bearing fitted with elastic bush, a, b) for film thickness values of over $5 \mu \mathrm{m}$ and c) for a smaller value - in this case the iteration diverges and no solution is available.

Attempts to solving the problem which consists in introduction of the so-called relaxation factor, did not give any satisfying result. In practice in the case in question it was not managed to achieve a stable solution for lubricating films thinner than $5 \div 7 \mu \mathrm{m}$. The calculations performed for the minimum acceptable lubricating gap of $5 \mu \mathrm{m}$ showed a much lower value of bearing capacity as compared with results of experimental tests (Fig. 4).

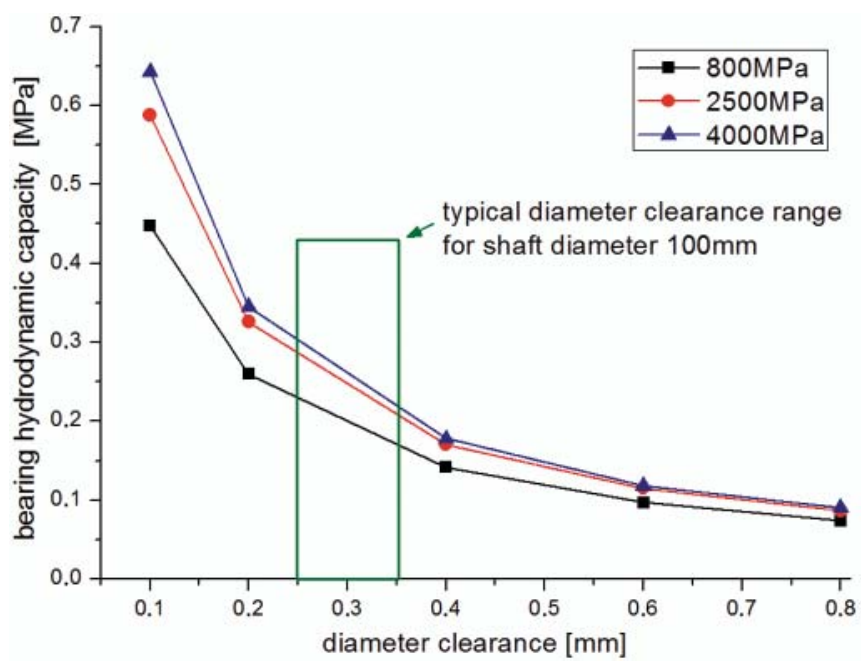

Fig. 4. The calculated maximum potential hydrodynamic capacity of water-lubricated bearing in function of bush material, bearing diameter clearance; shaft speed $11 \mathrm{rev} / \mathrm{s}$

However it is possible to reach certain conclusions by analyzing results of the calculated pressure distributions and bush elastic deformations (Fig. 5 and 6). As turns out, elastic deformation value may exceed that assumed for calculations of minimum film thickness amounting to $5 \mu \mathrm{m}$. In practice an elastic sag of bush results in dropping value of hydrodynamic pressure 
in lubricating film, that detrimentally affects bearing capacity. As appears, the zones close to bush edges are not elastically deformed due to hydrodynamic pressure action. Analyzing the experimentally tested bushes one observed significant wear in the zones, which is visible because sliding surface fast became polished in the places.

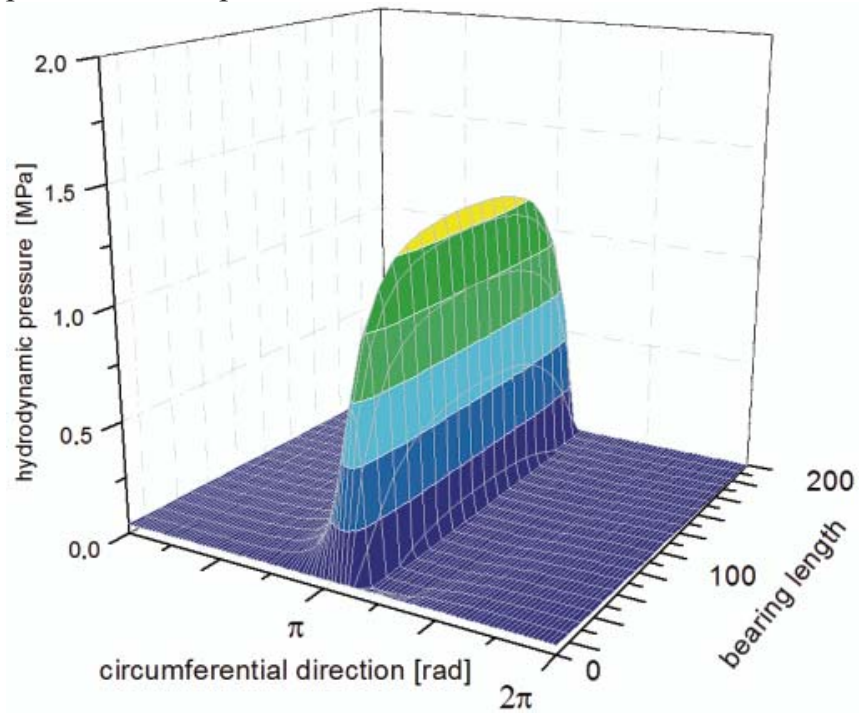

Fig. 5. The calculated pressure distribution in lubricating film of waterlubricated polymer bearing, (P1), in function of bush length (of $1 \div 200 \mathrm{~mm}$ ) and bush developed circumference (of $0 \div 2 \pi \mathrm{rad}$ )

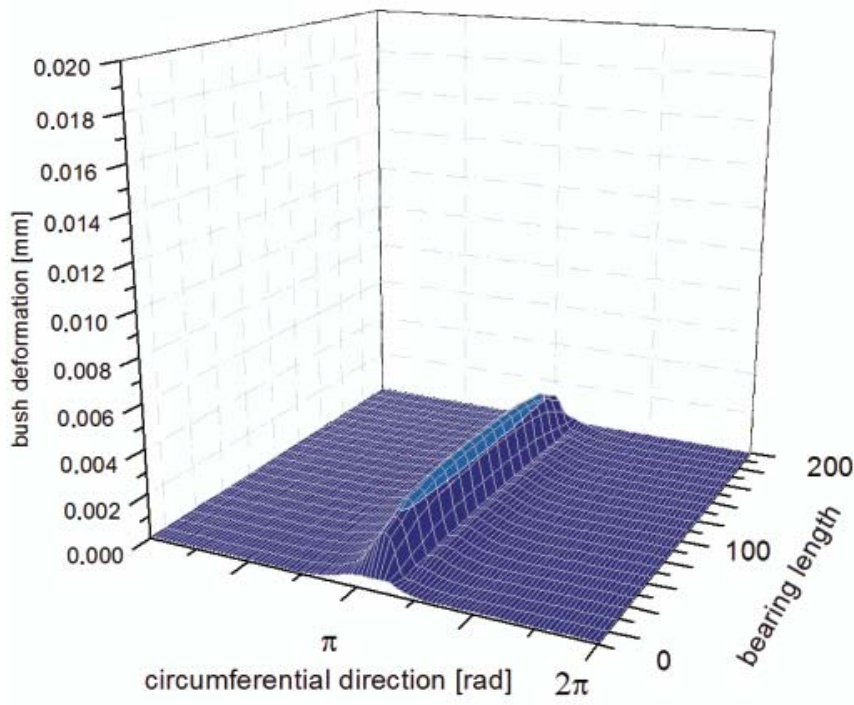

Fig. 6. The calculated distribution of elastic deformation of polymer bush of water-lubricated bearing, (P1), in function of bush length (of $1 \div 200 \mathrm{~mm}$ ) and bush developed circumference (of $0 \div 2 \pi \mathrm{rad}$ )

\section{PRESENTATION OF THE PROPOSED CALCULATION METHOD}

During searching subject-matter literature sources dealing with slide bearing systems, has been found several papers whose authors undertook the task to predict growing wear [6 $\div 10$ ]. Unfortunately the papers did not help in solving the wear problem of water-lubricated bearing and its effect on bearing capacity.

Basing on the earlier conducted projects one decided to perform calculations for the case when local wear occurs close to bush edges. To make it possible the classical algorithm of EHL method has been modified.

It was assumed that the minimum lubricating gap height was equal to $5 \mu \mathrm{m}$. If due to application of greater and greater load the lubricating gap decreases and its height becomes smaller than the assumed minimum then wear will occur. As a result of the process bush geometry undergoes permanent change. The schematic diagram of the relevant calculation software is shown in Fig. 7.

It was assumed that the method in question has to serve for calculating slide bearing capacity with accounting for edge wear. However if the procedure of application of greater and greater load is not terminated then the model will approach to the ridging effect reported in literature sources, when the journal rubs out a longitudinal groove in the bush. In the author's opinion the effect will not occur in the case of ship shaft line bearing as the shaft operates with various rotational speeds and the bearing's loading results from many different factors, e. g. ship operation in heavy weather conditions. Therefore working position of the shaft against the bush changes in operation and bush ovalization appears after long period of service (Fig. 8).

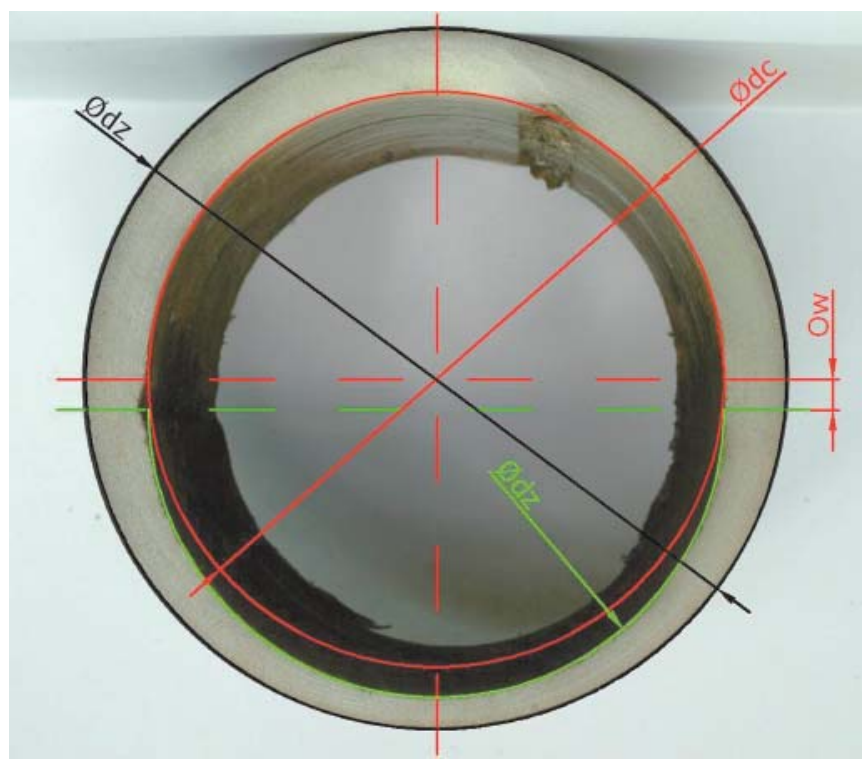

Fig. 8. Heavy-used water-lubricated slide bearing in which distinct bush ovalization took place and consequently the shaft altered its position down by the value Ow; ødz external bush diameter, ødc initial bush internal diameter, ødz worn area diameter

\section{THE TESTED BEARING AND ITS SIMULATED WORKING CONDITIONS}

The calculations were performed for two kinds of bush material of different values of module of shape elasticity. The analysis was performed for the polymer of shape elasticity module equal to about $2500 \mathrm{MPa}$ and the rigid composite of shape elasticity module equal to about $4500 \mathrm{MPa}$ (Tab. 1). As the lubricating medium fresh water of $5^{\circ} \mathrm{C}$ temperature and viscosity of about $1.55 \mathrm{mPa} \cdot \mathrm{s}$, was assumed. The calculations were conducted for the shaft rotational speed of $11 \mathrm{rev} / \mathrm{s}$.

\section{RESULTS OF THE CALCULATIONS}

Results of the calculations of hydrodynamic pressure distributions in lubricating film, and bush elastic deformations resulting from interaction between pressure field and wear field, are presented in Fig. $9 \div 12$. The developed surface diagrams were made for the lower part of the bush of the analyzed bearing (for circumference arc changeable from $0.5 \pi$ to $1.5 \pi$ ) and the bush length from 0 to $200 \mathrm{~mm}$. In order to make interpretation of the diagrams easier, values of elastic deformation and wear are shown within the same range, i. e. from 0 to $20 \mu \mathrm{m}$. Values of ultimate relative journal-bush eccentricity as well as results of the calculated bearing capacity are shown in Tab. 1. 
START

Data input, preliminary calculations

Bush size, shaft speed, water viscosity,

shaft eccentricity ratio $\varepsilon_{\text {start }}, \varepsilon_{\max }$, maximum expected load $L_{\max }$, minimum accepted film thickness $h_{\min }$.

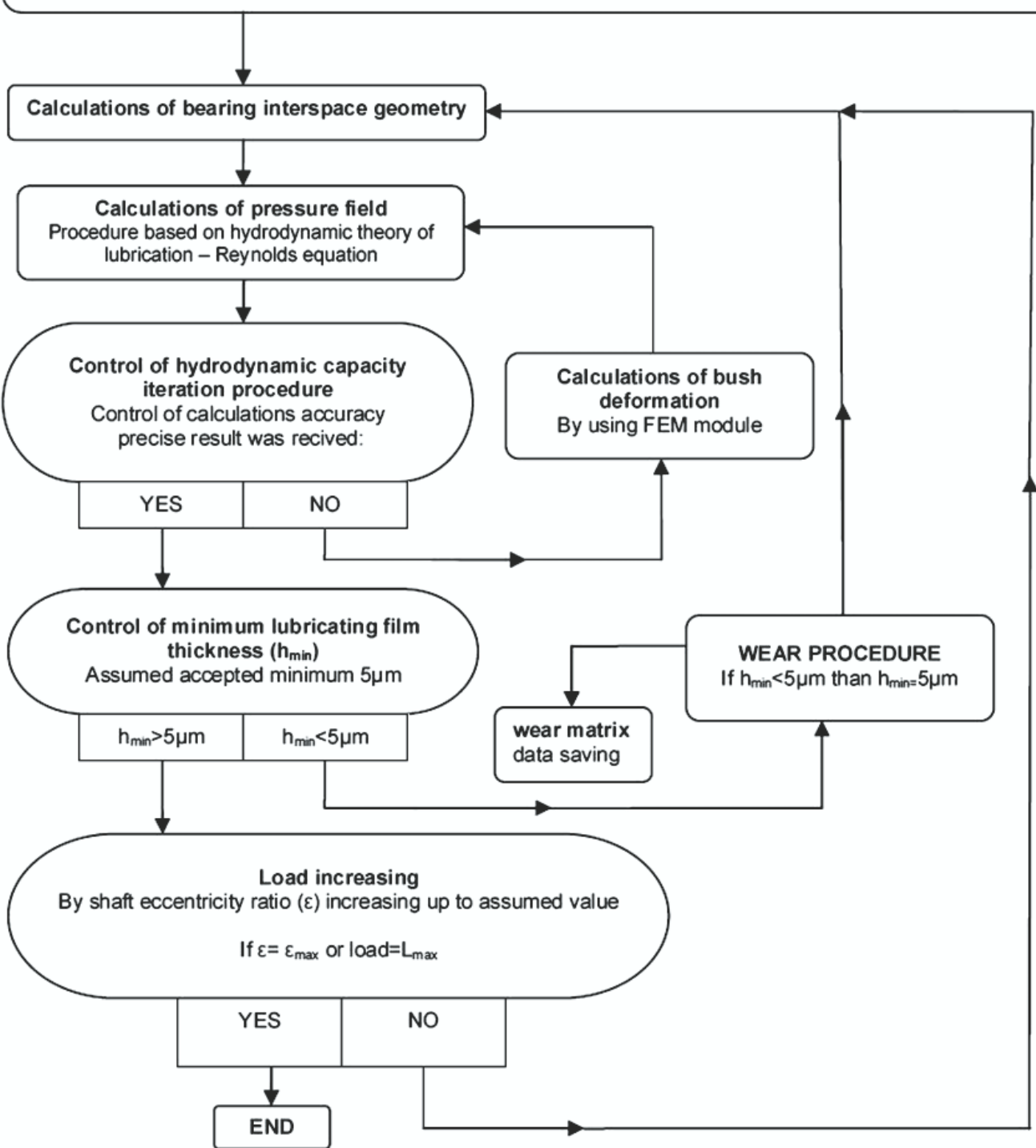

Fig. 7. The schematic diagram of the proposed calculation method of elastic hydrodynamic lubrication with accounted for bush local wear, (marked EHL $+W$

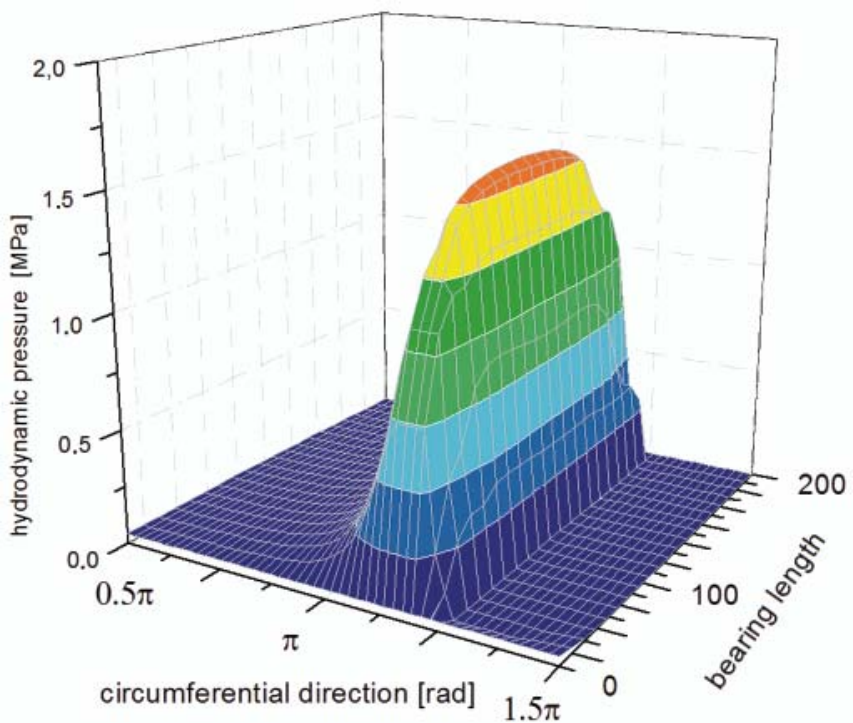

Fig. 9. The distribution of the hydrodynamic pressure in lubricating film for the bearing fitted with elastic bush of the elasticity module of $2500 \mathrm{MPa}$, $(P 2)$, at the shaft rotational speed of $11 \mathrm{rev} / \mathrm{s}$

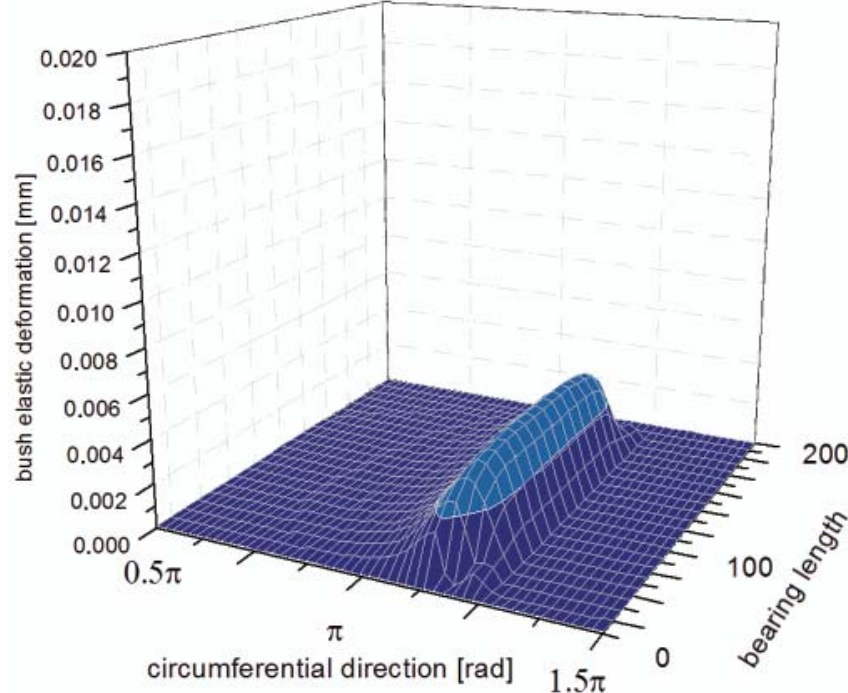

Fig. 10. The distribution of elastic deformation for the bush of the elasticity module of $2500 \mathrm{MPa},(\mathrm{P2})$, at the shaft rotational speed of $11 \mathrm{rev} / \mathrm{s}$ 
Tab. 1. Input data and results of the calculations for two kinds of the analyzed polymer bush of different values of shape elasticity module

\begin{tabular}{|c|c|c|c|c|c|c|c|}
\hline No. & Bearing code & $\begin{array}{l}\text { Bush } \\
\text { material } \\
\text { type }\end{array}$ & $\begin{array}{l}\text { Module of } \\
\text { elasticity }\end{array}$ & $\begin{array}{c}\text { Bearing } \\
\text { clearance/shaft } \\
\text { diameter } / \text { bush } \\
\text { thickness }[\mathrm{mm}]\end{array}$ & $\begin{array}{l}\text { Shaft } \\
\text { eccentricity } \\
\text { ratio }(\varepsilon)\end{array}$ & $\begin{array}{l}\text { Maximum } \\
\text { wear }[\mu \mathrm{m}]\end{array}$ & $\begin{array}{c}\text { Calculations } \\
\text { results - maximum } \\
\text { hydrodynamic capacity }\end{array}$ \\
\hline 1 & $\mathrm{P} 1$ & \multirow{2}{*}{ polymer } & \multirow{2}{*}{$2500 \mathrm{MPa}$} & \multirow{4}{*}{$0.3 / 100 / 12$} & 0.965 & 0 & $5537 \mathrm{~N}$ \\
\hline 2 & $\mathrm{P} 2$ & & & & 0.98 & 16 & $6320 \mathrm{~N}$ \\
\hline 3 & $\mathrm{C} 1$ & \multirow{2}{*}{ composite } & \multirow{2}{*}{$4500 \mathrm{MPa}$} & & 0.965 & 0 & $5929 \mathrm{~N}$ \\
\hline 4 & $\mathrm{C} 2$ & & & & 0.98 & 13 & $6394 \mathrm{~N}$ \\
\hline
\end{tabular}

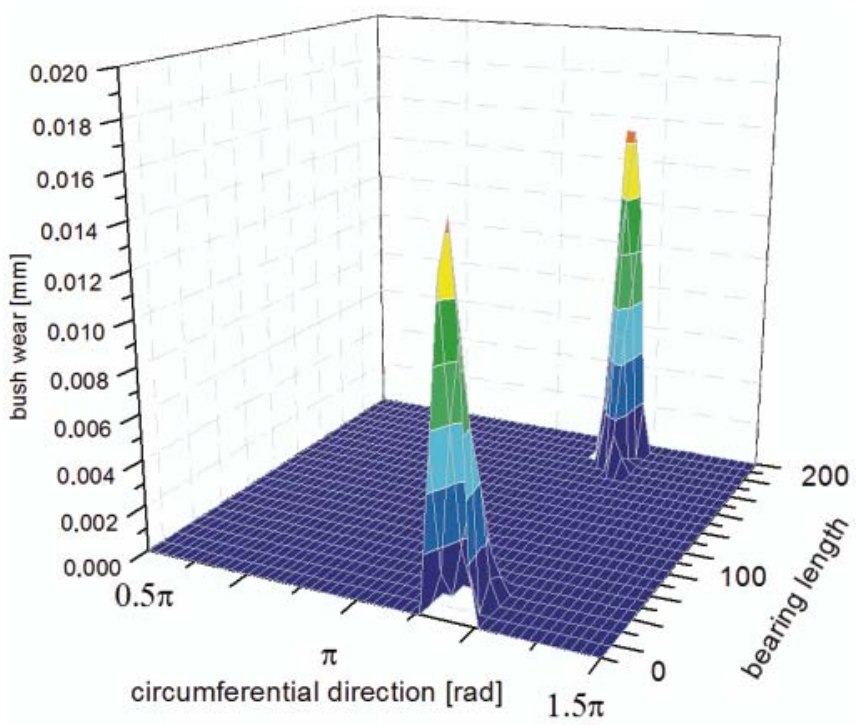

Fig. 11. The wear field for the bush of the elasticity module of 2500 $M P a,(P 2)$, at the shaft rotational speed of $11 \mathrm{rev} / \mathrm{s}$; the wear occurred close to the bearing's edges only

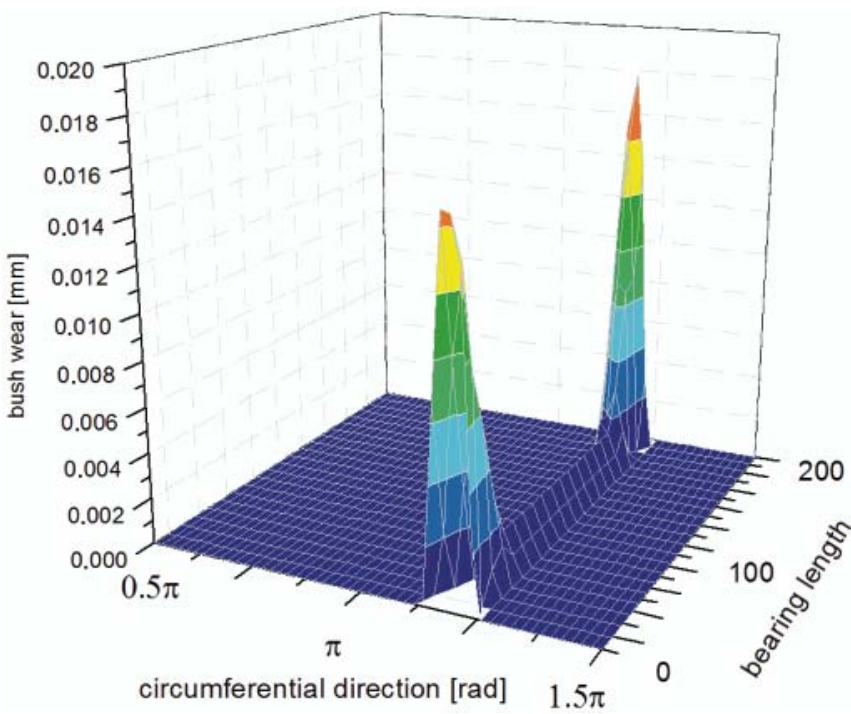

Fig. 12. The wear field for the bush of the elasticity module of $2500 \mathrm{MPa}$, (P2), the wear occurred also along the whole breadth of the bearing; this is the case when the calculations have been discontinued; the shaft rotational speed of $11 \mathrm{rev} / \mathrm{s}$; the calculated bearing capacity of $6500 \mathrm{~N}$

\section{CONCLUSIONS}

The proposed calculation method based on the EHL model extended by a module which accounts for bush wear, made it possible to obtain calculation results for the conditions in which the classical model ceases to be effective.

In the author's opinion the proposed calculation method is reliable as the phenomenon of local seizing close to bush edges was observed in the experimentally tested bearings.

The performed calculations demonstrated that the accounting for bush local wear makes it possible to increase theoretical bearing capacity by $7 \%$ in the case of the more rigid composite material and by nearly $15 \%$ for the less rigid one (polymer).

The calculated bearing hydrodynamic capacity with accounted for bush local wear reaches the value of $0.316 \mathrm{MPa}$. On the basis of experimental tests it is possible to conclude that the maximum hydrodynamic capacity of bearings of the kind may reach even the value of $0.5 \mathrm{MPa}$. Therefore it should be considered why not to carry out calculations for smaller values of lubricating film thickness and greater values of bush wear located not only close to its edges but also along the whole contact line between shaft and slide bush (Fig. 12).

The proposed calculation method may be applied also in the case of the skewed shaft against bush, i.e. in which the method may be especially helpful.

\section{BIBLIOGRAPHY}

1. Litwin W.: Marine water lubricated main shaft bearings, problems, theoretical and experimental research. Polish Maritime Research No. 4, Vol. 16, 2009

2. Litwin W.: Water - An Extraordinary, Ordinary Lubrication Liquid. Influence Of Water Salinity, Pressure And Temperature On Water Lubricated Bearings Properties. ASME/STLE International Joint Tribology Conference October $17 \div 20,2010$, San Francisco, California, USA

3. Litwin W.: Influence of main design parameters of ship propeller shaft water-lubricated bearings on their properties. Polish Maritime Research No. 4 (67), Vol. 17, 2010

4. Litwin W.: Water Lubricated Marine Stern Tube Bearings - Attempt At Estimating Hydrodynamic Capacity. ASME/STLE International Joint Tribology Conference October $19 \div 21,2009$, Memphis, Tennessee, USA

5. Litwin W.: Marine water lubricated stern tube bearings - calculations and measurements of heavy loaded bearings. STLE/ASME International Joint Tribology Conference October $20 \div 22$, 2008, Miami, Florida, USA

6. Ramalho A.: A geometrical model to predict the wear evolution of coated surfaces. Wear, 264 (2008)

7. Sfantos G. K., Aliabadi M. H.: Wear simulation using an incremental sliding Boundary Element Method, Wear, 260 (2006)

8. Nikolakopoulos P. G., Papadopoulos C. A.: A study of friction in worn misaligned journal bearings under severe hydrodynamic lubrication. Tribology International, 41 (2008)

9. Bouyer J., M. Fillon, and I. Pierre-Danos: Influence of Wear on the Behavior of a Two-Lobe Hydrodynamic Journal Bearing Subjected to Numerous Startups and Stops. ASME Journal of Tribology, January 2007, Vol. 129

10.Wang, W., Wong, P.L., Guo, F.: Application of partial elastohydrodynamic lubrication analysis in dynamic wear study for running-in.Wear, 2004,Vol. 257.

\section{CONTACT WITH THE AUTHOR}

Wojciech Litwin, Ph. D.

Faculty of Ocean Engineering and Ship Technology

Gdansk University of Technology Narutowicza 11/12

80-233 Gdansk, POLAND

e-mail: wlitwin@pg.gda.pl 